Proc. of the X Int. Conf. - Ion Implantation and other Applications of Ions and Electrons, Kazimierz Dolny 2014

\title{
Tribological Properties of AISI 316L Steel Surface Layer Implanted with Rare Earth Element
}

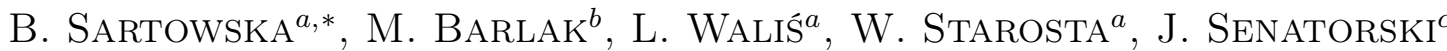 \\ AND A. KOSIŃSKA ${ }^{b}$ \\ ${ }^{a}$ Institute of Nuclear Chemistry and Technology, Dorodna 16, 03-195 Warsaw, Poland \\ ${ }^{b}$ National Centre for Nuclear Research, A. Soltana 7, 05-400 Otwock/Swierk, Poland \\ ${ }^{c}$ Institute of Precision Mechanics, Duchnicka 3, 01-796 Warsaw, Poland
}

\begin{abstract}
Stainless steels with their very good corrosion resistance are used in nuclear, petrochemical, chemical, pulp and paper chemical industries as well as in food processing and others. Unfortunately, poor tribological properties of this kind of steel can be the limitation in the situations in which wear can be responsible for material degradation, like corrosion-erosion. Improvement of the wear resistance of austenitic stainless steels can be achieved using different methods of surface modification, for example: enrichment of the surface layer with reactive elements. Rare earth elements were implanted to AISI 316L austenitic stainless steel using the MEVVA type implanter (65 kV). Different rare earth elements implanted doses: $10^{15}, 5 \times 10^{15}$, and $5 \times 10^{16}$ ion $/ \mathrm{cm}^{2}$ were applied. Initial and modified surfaces were investigated using scanning electron microscopy, elemental analysis with the energy dispersive spectroscopy method, X-ray diffraction analysis and the Rutherford backscattered spectroscopy. Tribological properties were investigated using the Amsler method. The most important result was that the surface layers of AISI 316L steel implanted with rare earth elements showed improvement of tribological properties as compared with the initial material.
\end{abstract}

DOI: $10.12693 /$ APhysPolA.128.923

PACS: 62.20.Qp, 68.55.Nq, 81.40.Pq

\section{Introduction}

Modification of technical materials surfaces is applied to change their surface properties. The concentration of chosen elements, structure of material or both can be changed. Austenitic stainless steels with very good corrosion resistance in different environments have industrial applications, for example: nuclear and petrochemical, pulp and paper chemical industries as well as food and chemical processing and others. Poor tribological properties of austenitic stainless steels limited their applications. Improvement of the wear resistance of austenitic stainless steels can be achieved using enrichment of the surface layer with reactive elements. It is well known that high oxygen affinity elements such as Y, Ce, La, Er and other rare earth elements (REE) added to steels in small amounts can improve their resistance to electrochemical corrosion [1], high temperature oxidation [1-6], wear $[7,8]$. The amount of REE addition has to be precisely controlled. There are no positive effects if the REE addition is too small. If the REE addition is too high the negative effects are observed, like embrittlement increase and mechanical properties deterioration. REE can be incorporated into the surface area of materials using different methods of surface treatment: ion implantation $[1,3,4]$, plasma immersion ion implantation [2], solgel coating $[4,9]$, metal organic chemical vapour deposition [10-13], plasma beams application [2, 5, 14], pack cementation [3].

*corresponding author; e-mail: b.sartowska@ichtj.waw.pl
The results of incorporation of $\mathrm{REE}(\mathrm{Ce}+\mathrm{La})$ as active elements into austenitic stainless AISI 316L using the conventional ion implantation technique with a MEVVA type implanter are presented in this work.

\section{Experiment}

Austenitic stainless steel AISI 316L with the main elements concentration (in wt\%) $\mathrm{Cr}-16.3, \mathrm{Ni}-11.5$, $\mathrm{Mo}-2.03, \mathrm{Mn}-1.3, \mathrm{Fe}$ - balance was used as the substrate. The mishmetal (MM) with the composition (in wt\%): $\mathrm{Ce}-65.3, \mathrm{La}-34.0$, and the balance of $\mathrm{Fe}, \mathrm{Mg}$, and $\mathrm{Pr}$ was used as a REE source. The ratio of $\mathrm{Ce}(\mathrm{wt} \%) / \mathrm{La}(\mathrm{wt} \%)$ was assumed to be 2:1. REE were incorporated into the surface of steel samples.

The implantation of REE ions was carried out using a MEVVA type TITAN implanter with direct beam, described in detail elsewhere [15] at an accelerating voltage of $65 \mathrm{kV}$. To avoid overheating effects samples were clamped onto a water-cooled stainless steel plate and the ion current densities were kept below $10 \mathrm{~mA} / \mathrm{cm}^{2}$, so the substrate temperature did not exceed $200^{\circ} \mathrm{C}$. The base pressure in the vacuum chamber was about $(2-5) \times 10^{-4} \mathrm{~Pa}$. Nitrogen gas of $99.9 \%$ purity was used as the working gas. Nitrogen was treated as the reactive element, often used in surface modification of technical materials. The applied ion doses were $10^{15}, 5 \times 10^{15}$, and $5 \times 10^{16} \mathrm{ion} / \mathrm{cm}^{2}$. The samples were characterized by: the Quantax 400 EDS system (Bruker, Germany) for elemental concentrations determination, D8 Advanced (Bruker, Germany) diffractometer $\left(\omega=10^{\circ}, \mathrm{Cu} K_{\alpha}\right)$ for materials structure determination and Rutherford backscattered spectroscopy (RBS) (energy $(1.77 / \mathrm{ch}+44) \mathrm{keV}$, detector resolution $19.5 \mathrm{keV}$, solid angle $3.053 \mathrm{msv}$ ) for 
elemental composition and thickness of the modified surface layer determination. Wear resistance measurements were performed using the Amsler method with A135 Amsler machine (sliding friction distance $3000 \mathrm{~m}$, constant load 5 daN, $41 \mathrm{Cr} 4$ steel counter-sample).

\section{Results and discussion}

Concentrations of Ce, La and REE ( $\mathrm{Ce}+\mathrm{La}$ ) incorporated into the surface layer of samples increased with the increasing doses, see Fig. 1. Character of the observed dependence was the same for REE and single elements. Simultaneously, nitrogen ions were incorporated into the modified surface layer. Nitrogen concentrations were: $1.50,1.55$ and 2.6 for REE implantation with $10^{15}$, $5 \times 10^{15}$ and $5 \times 10^{16}$ ion $/ \mathrm{cm}^{2}$, respectively.

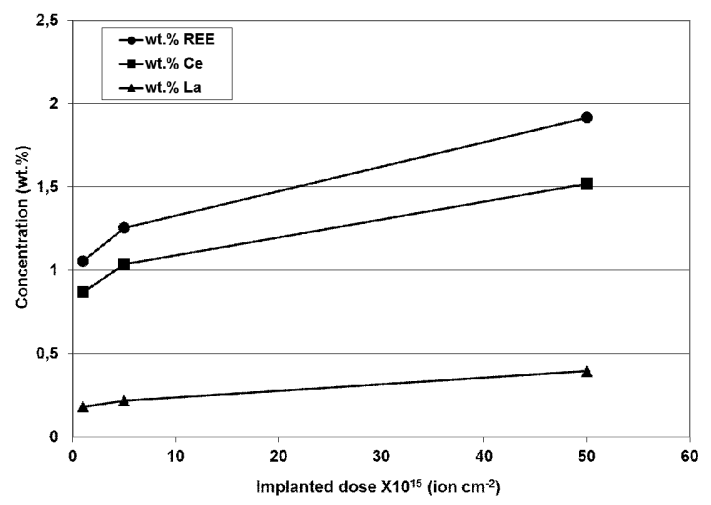

Fig. 1. REE concentration in the surface layer of AISI 316L steel after ion implantation vs. REE implanted dose.

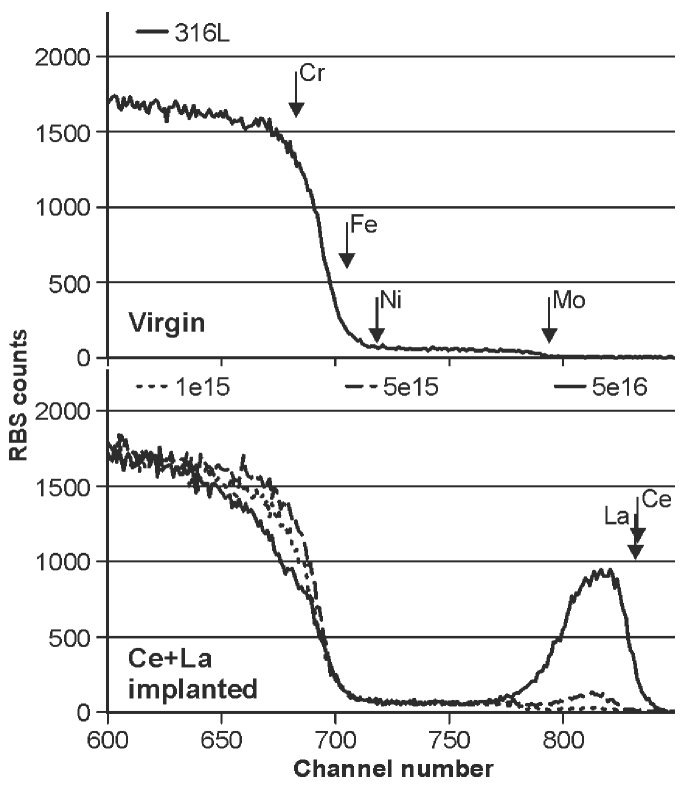

Fig. 2. RBS spectra for initial and modified materials.

The RBS spectra of the initial and REE (Ce + La) implanted samples with the applied doses are shown in Fig. 2. The upper part shows the spectra of initial
AISI 316L steel with the appropriately marked positions of main steel components. The lower part shows the experimental spectra of the samples REE implanted with a marked threshold positions of the implanted elements. The RBS spectra were analyzed using the SIMNRA code. The returned doses of implanted elements were very similar to the implanted doses for all cases, also. The RBS spectra were analyzed assuming that the ratio of $\mathrm{Ce}$ and La elements concentration was $2: 1$. The thickness of the layer with the implanted elements, calculated for Fe substrate was about $75 \mathrm{~nm}$ for all applied doses.

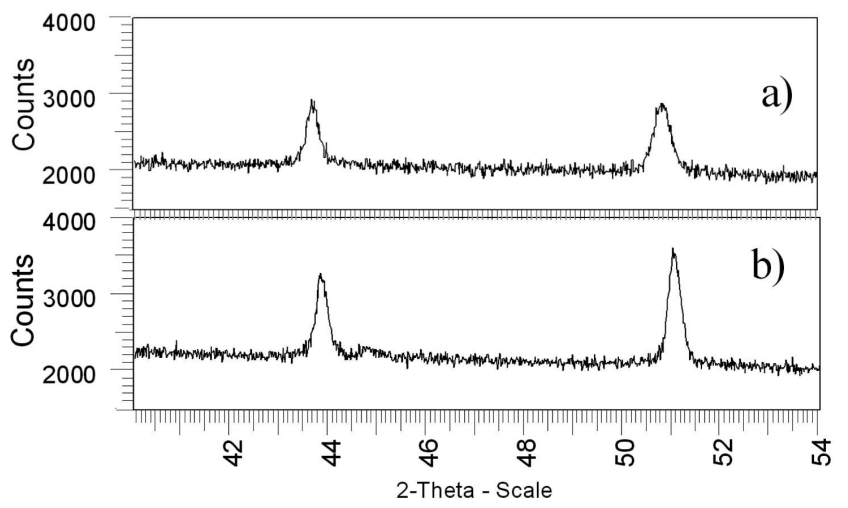

Fig. 3. GXRD spectra of AISI 316L steel for (a) untreated and (b) REE implanted dose $5 \times 10^{15} \mathrm{ion} / \mathrm{cm}^{2}$.

The first two peaks of the GXRD spectra for untreated and modified with the dose $5 \times 10^{15}$ ion $/ \mathrm{cm}^{2}$ material are presented in Fig. 3. In the case of initial material the clearly visible peaks at $2 \theta$ positions: 43.9 degrees (111) and 51.1 degrees (200) were observed. The spectra analysis confirms the presence of fcc phase - austenitic structures - with the space symmetry group $F m-3 m$. It is clear that in the initial material - austenitic stainless steel was investigated. In the case of modified material peaks characteristic of fcc structure - (111) and (200) confirm that after REE ion implantation austenitic phase was present in the surface layer of steel. The data analysis using the Topas3 programme allowed to determine the lattice parameter, see the Table. The increase of the austenite lattice parameter value was observed with the applied doses. The authors assumed that the changes in the crystallites size as well as presence of internal stress in the modified surface layer is the reason of increase of austenite lattice parameter. The lattice parameter increased by $0.4 \%$ for the $10^{15} \mathrm{ion} / \mathrm{cm}^{2}$ dose and by $0.5 \%$ for the both applied higher doses. At the fixed angle of measurements (10 degrees) the beam penetrated the investigated layer to the depth of $74 \mathrm{~nm}$.

Changes of the linear wear observed for all investigated samples show the linear character, see Fig. 4 . It can be seen that there was no effect on the wear resistance value in the case of the dose $10^{15} \mathrm{ion} / \mathrm{cm}^{2}(1.06 \mathrm{wt} \%$ of REE incorporation). It is quite different in the case of REE implanted with doses of $5 \times 10^{15}$ and $5 \times 10^{16}$ ion $/ \mathrm{cm}^{2}$ with 1.26 and $1.92 \mathrm{wt} \%$ REE incorporation, respectively. 
TABLE

Value of the austenite lattice parameter and its changes due to the dose of REE ion implantation.

\begin{tabular}{c|c|c|c}
\hline \hline \multicolumn{4}{|c}{ REE implanted } \\
\hline Dose $\left[\right.$ ion $\left./ \mathrm{cm}^{2}\right]$ & $\begin{array}{c}\text { Lattice } \\
\text { parameter }[\AA]\end{array}$ & Change $[\AA]$ & $\%$ Change \\
\hline initial & 3.5830 & & \\
$10^{15}$ & 3.5980 & 0.0150 & 0.42 \\
$5 \times 10^{15}$ & 3.6018 & 0.0188 & 0.53 \\
$5 \times 10^{16}$ & 3.6020 & 0.0180 & 0.53
\end{tabular}

In these both cases the smaller value of linear wear that is higher wear resistance was observed as compared with that of the initial material. At the end of carried out investigations the linear wear was by about $35 \%$ and $60 \%$ lower for REE implanted with the doses $5 \times 10^{15}$ and $5 \times 10^{16}$ ion $/ \mathrm{cm}^{2}$, respectively. The obtained results are in agreement with the fact that it is necessary to control precisely the REE amount, as mentioned in the Introduction part. The dose $10^{15}$ ion $/ \mathrm{cm}^{2}$ was probably too small to evoke positive results.

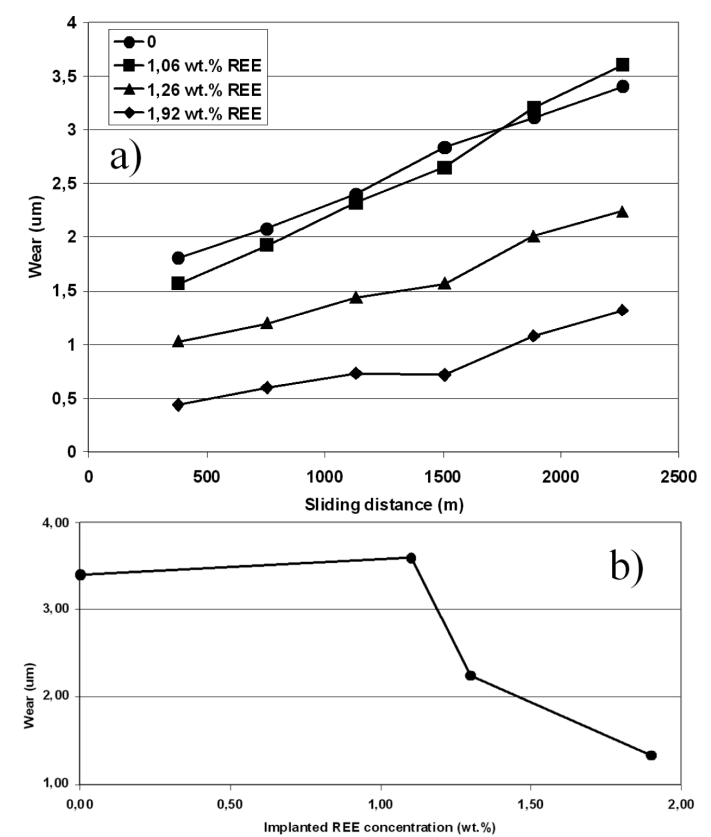

Fig. 4. Results of linear wear of AISI 316L steel REE implanted (a) changes in linear wear during the measurements, (b) wear value at the end of wear measurements vs concentration of incorporated REE.

Authors considered two facts: (i) similar nitrogen concentration (1.50 and $1.55 \mathrm{wt} \%$ ) and (ii) different results of the wear tests $(3.55$ and $2.25 \mu \mathrm{m}$ linear wear) for the samples with the incorporated REE doses $10^{15}$ and $5 \times 10^{15}$ ion $/ \mathrm{cm}^{2}$, respectively. The authors assumed that the role of nitrogen is not crucial. The main achievement in improvement of the wear resistance was caused by the REE incorporation. The detailed explanation of the role of nitrogen ought to be done and the next experiments and investigations are planned.

The applied surface modification technique changed the surface layer of the base material in some ways. The first point is incorporation of new elements to the surface layer, here: REE $(\mathrm{Ce}+\mathrm{La})$ and nitrogen. The second point is that elements incorporated by ion implantation evoke internal stress in the crystal lattice. The third point is that radiation effects and compressive stress area have the bigger range that determined by RBS and XRD thickness of modified layer, described above.

\section{Conclusions}

1. Implantation of REE (Ce + La) into AISI 316L stainless steel with the doses: $10^{15}, 5 \times 10^{15}$ and $5 \times 10^{16} \mathrm{ion} / \mathrm{cm}^{2}$ leads to formation of the enriched with dopants near-surface layer.

2. Austenitic phases (fcc) were identified in the modified layer with the increased lattice parameters with the increasing implantation dose as compared with the initial material.

3. The obtained modified surface layers enriched with $\operatorname{REE}(\mathrm{Ce}+\mathrm{La})$ with the dose of $5 \times 10^{15}$ and $5 \times 10^{16} \mathrm{ion} / \mathrm{cm}^{2}$ showed significant improvement of the wear resistance by $35 \%$ and $60 \%$, respectively, as compared with the initial material.

4. The applied dose $10^{15} \mathrm{ion} / \mathrm{cm}^{2}$ was too small to observe a positive effect of the REE presence on tribological properties of the modified surface.

\section{Acknowledgments}

The work was partially supported by the project Support of Public and Industrial Research Using Ion Beam Technology (SPIRIT) under EC contract 227012 and by the Polish Ministry of Science and Higher Education (Decision 2871/SPIRIT/2013/0).

\section{References}

[1] C.M. Abreu, M.J. Cristobal, X.R. Novoa, G. Pena, M.C. Perez, R.J. Rodriguez, Surf. Coat. Technol. 158, 582 (2002).

[2] D. Cleugh, C. Blawert, J. Steinbach, H. Ferkel, B.L. Mordike, T. Bell, Surf. Coat. Technol. 142144, 392 (2001).

[3] D. Alman, P. Jablonski, Int. J. Hydrogen Energy 32, 3743 (2007).

[4] F. Riffard, H. Buscail, E. Caudron, R. Cue, C. Issartel, S. Perriera, Appl. Surf. Sci. 199, 107 (2002).

[5] J. Piekoszewski, B. Sartowska, M. Barlak, P. Konarski, L. Dąbrowski, W. Starosta, L. Walis, Z. Werner, C. Pochrybniak, K. Bochenska, P. Stoch, W. Szymczyk, Surf. Coat. Technol. 206, 854 (2011). 
[6] A. Vesel, M. Mozetic, A. Drenik, N. Hauptman, M. Balat-Pichelin, Appl. Surf. Sci. 255, 1759 (2008).

[7] X.H. Cheng, C.Z. Xie, Wear 254, 415 (2003).

[8] H. Liu, M.F. Yan, D.L. Wu, J. Mater. Proces. Technol. 210, 784 (2010).

[9] W. Qu, J. Li, D.G. Ivey, J. Power Source 138, 162 (2004).

[10] S. Chevalier, G. Bonnet, F. Dufour, J.P. Larpin, Surf. Coat. Technol. 100/101, 208 (1998).

[11] P. Picardo, S. Chevalier, R. Molins, M. Viviani, G. Caboche, A. Barbucci, M. Sennour, R. Amendola, Surf. Coat. Technol. 201, 4471 (2006).
[12] S. Fontana, R. Amendola, S. Chevalier, J. Power Sources 171, 652 (2007).

[13] A. Balland, P. Gannon, M. Deibert, S. Chevalier, G. Caboche, S. Fontana, Surf. Coat. Technol. 203 , 3291 (2009)

[14] Z. Werner, J. Piekoszewski, W. Szymczyk, Vacuum 63, 701 (2001).

[15] S.P. Bugaev, A.G. Nikolaev, E.M. Oks, P.M. Schanin, G.Y. Yushkov, Rev. Sci. Instrum. 65, 3119 (1994). 